\title{
Comparison of the Effectiveness of Two Modalities of Group Delivery of Emotional Freedom Technique (EFT) Intervention for Food Cravings: Online versus In-Person
}

\author{
P. Stapleton*, M. Stewart \\ School of Psychology, Bond University, Gold Coast, Queensland, Australia \\ Email: *pstaplet@bond.edu.au
}

How to cite this paper: Stapleton, P., \& Stewart, M. (2020). Comparison of the Effectiveness of Two Modalities of Group Delivery of Emotional Freedom Technique (EFT) Intervention for Food Cravings: Online versus In-Person. Open Journal of Social Sciences, 8, 158-181.

https://doi.org/10.4236/jss.2020.82014

Received: November 26, 2019

Accepted: February 25, 2020

Published: February 28, 2020

Copyright $\odot 2020$ by author(s) and Scientific Research Publishing Inc. This work is licensed under the Creative Commons Attribution International License (CC BY 4.0).

http://creativecommons.org/licenses/by/4.0/

\begin{abstract}
Recent research has demonstrated the effectiveness of Emotional Freedom Techniques (EFT), to address overeating behaviours in obese and overweight individuals both in-person (Church \& Brooks, 2010; Stapleton et al., 2011, 2012, 2016, 2017) and online (Church, Stapleton, Sheppard \& Carter, 2018; Church \& Wilde, 2013). The aim of the present study was to determine whether an online EFT program was as efficacious as the in-person treatment. This was achieved by comparing data from a randomised clinical trial (RCT) for an in-person EFT intervention for weight management (Stapleton et al., 2016), with an equivalent online RCT. Each program targeted food cravings, the subjective power of food, dietary restraint, body mass index, weight, somatic symptomology, anxiety, and depression. Results indicate both modalities were comparable in efficacy and both groups experienced significant reductions from pre-intervention to post-intervention, with reductions remaining significant at follow ups for food cravings, power of food, depression and weight, with minor differences observed at post-intervention or 6-month follow up for dietary restraint, somatic symptoms, anxiety and body mass index. Follow-up analyses revealed a significant effect of depression, anxiety and weight on attrition in the online treatment group.
\end{abstract}

\section{Keywords}

Food Cravings, Anxiety, Online Therapy, Emotional Freedom Techniques

\section{Introduction}

Obesity is a global health epidemic responsible for increased rates of preventable 
and non-communicable diseases, lowered life expectancies and poor quality of life for those affected (Australian Medical Association (AMA), 2016). Obesity is suggested to be caused by a long term imbalance between energy intake and energy expenditure, with individual body weight determined by an interacting range of biological, social, environmental and psychological factors (Spiegelman \& Flier, 2001). The adverse consequences of obesity are well established with research consistently demonstrating correlations between obesity and a range of cardiovascular disease, respiratory disease, vascular disease, certain cancers, musculoskeletal disorders, type 2 diabetes, and premature mortality (Kent et al., 2017; World Health Organisation (WHO), 2017).

Given this worldwide health crisis, historical ways of viewing obesity that focus solely on biological and genetic determinants of weight, need to be revised (Locke et al., 2015). Increases in the rates of overweight and obesity in recent decades have been so rapid that biological or genetic factors alone can no longer be considered as the major contributor to this epidemic (Shaw, O'Rourke, Del Mar, \& Kenardy, 2005). Eating behaviour is accepted as a complicated process that may be modulated by internal biological and psychological factors, at the same time as it is influenced by social and environmental factors (Cappelleri et al., 2009).

Interventions for weight reduction have typically focused on addressing the behavioural aspects of obesity by targeting diet and/or exercise (WHO, 2016). Dieting alone has demonstrated low efficacy for long term weight loss due to low long-term compliance (McAuley et al., 2006). The failure of traditional weight management programs to address the internal psychological determinants contributing to weight gain has led to increased interest into the individual psychological factors that impact health and weight related behaviours (Linardon, Wade, de la Piedad, \& Brennan, 2017). The only therapies to have been widely researched in this area are behavioural therapies (BT), cognitive therapy (CT) or cognitive behavioural therapy (CBT; Shaw et al., 2005). However, in order to produce the long term meaningful effects that CBT can offer, extensive periods of clinical contact are required which translates to higher costs and long term time commitments (Sojcher, Fogerite, \& Perlman, 2012). As a result of this limitation of time and expense, a new range of low-cost psychological treatments are being investigated (Sojcher et al., 2012).

\subsection{Emotional Freedom Techniques (EFT)}

EFT is a novel stress reduction treatment that has been researched across a range of concerns (Feinstein, 2012). EFT requires the client to use two fingers to stimulate acupoints located around the face and upper part of the body with a two-finger tapping process (Craig, 2010). The process borrows from established techniques, including acupuncture, cognitive and exposure therapy (Church, 2013).

In the EFT process clients tap on a point on the side of the hand (see Figure 1) 


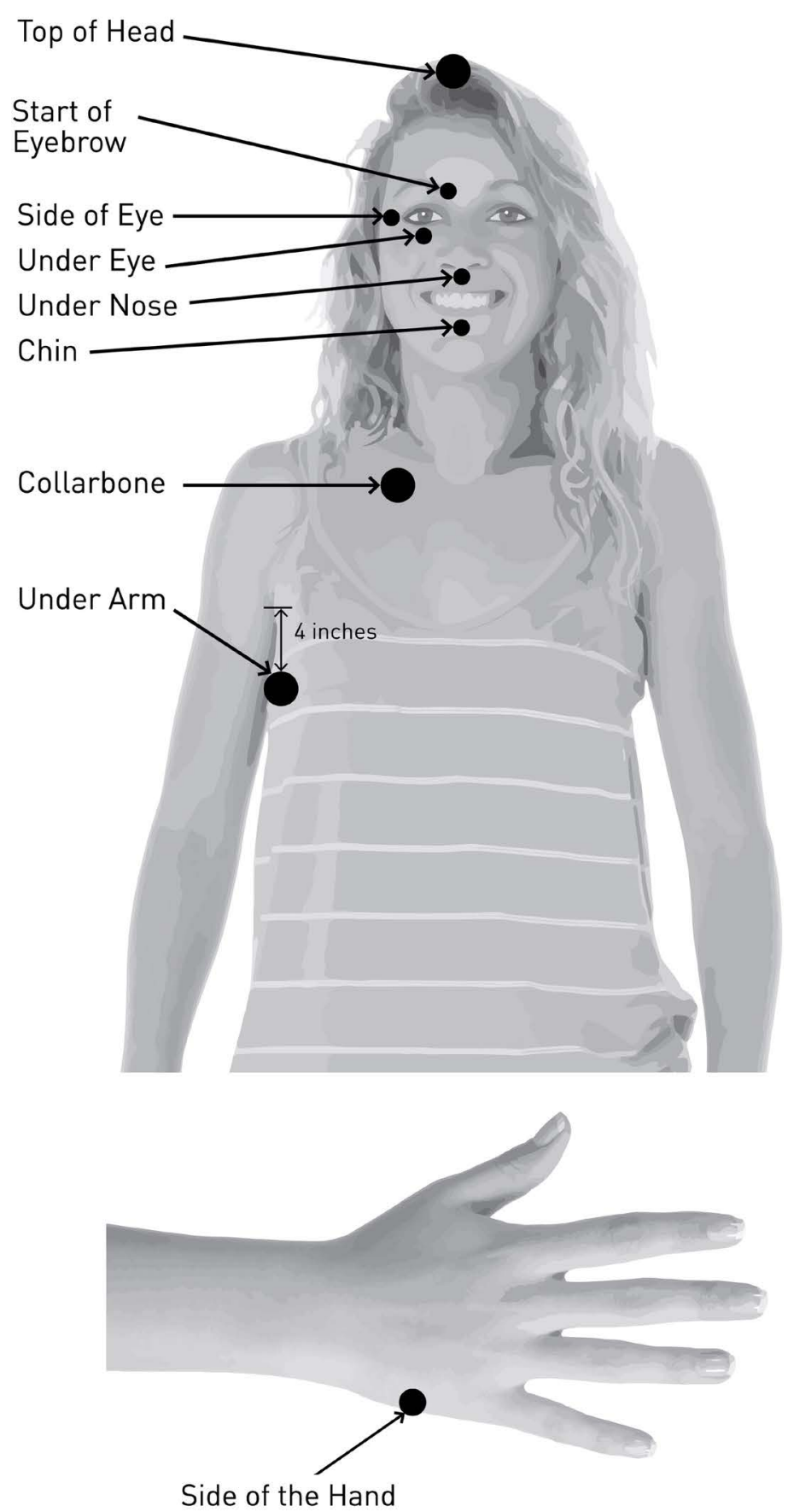

Figure 1. Eight Tapping Points (and side of hand). Copyright 2018 by Peta Stapleton. Reprinted with permission.

while they voice a set-up statement that summarises the issue they are currently experiencing, alongside a self-acceptance statement. For example, they may say, "Even though I have this issue (usually named specifically), I accept myself." Typically, the client will repeat the set up statement three times before tapping through the eight acupoints, tapping each point approximately seven times while repeating a reminder phrase (i.e.: a shortened version of the original issue e.g., this craving). Prior to beginning the process and immediately after, the client 
rates the intensity of their emotional experience on a subjective units of distress (SUDS; Wolpe, 1973) scale of 0 (no distress) to 10 (intense distress). The client continues tapping through the eight points until the level of intensity is reduced to 0 (Church, 2013).

Studies investigating EFT in the treatment of a number of conditions such as tension headaches (Bougea et al., 2013), anxiety (Patterson, 2016), depression (Chatwin, Stapleton, Porter, Devine, \& Sheldon, 2016). PTSD (Church, Sparks, \& Clond, 2016), phobias (Wells, Polglase, Andrews, Carrington, \& Baker, 2003), and food cravings (Stapleton et al., 2012; Stapleton et al., 2016) have reported positive outcomes. Meta-analysis have verified the effectiveness of EFT in the treatment PTSD in veterans (Sebastian \& Nelms, 2017), depression (Nelms \& Castel, 2016) and for anxiety (Clond, 2016).

\subsection{EFT for Food Cravings}

An initial study of 216 healthcare workers attending an EFT one-day workshop resulted in a significant reduction in cravings for a range of food substances, alcohol and tobacco from pre- to post-intervention (Church \& Brooks, 2010). A RCT was then conducted in overweight and obese participants against a wait-list control group (Stapleton et al., 2011). Over a four-week period the participants in the EFT condition received in-person weekly group sessions of two-hour duration. Results demonstrated that EFT was associated with significant decreases across food cravings and improvements in restraint ability, from pre-treatment to post-treatment when compared to a waitlist control (Stapleton et al., 2012).

A non-inferiority RCT compared EFT to CBT in overweight and obese participants, with results compared to a non-clinical community sample (Stapleton, Bannatyne, Porter, Urzi, \& Sheldon, 2016). Results indicated that both CBT and EFT decreased the presence of food cravings, increase participants' feeling of power over food in their environment and to reduced dietary restraint all to within levels comparable to the community sample (Stapleton et al., 2016). At the end of the eight-week program the CBT group had significantly lower anxiety scores but this effect was not maintained at six and twelve-month follow-up points (Stapleton et al., 2017). The EFT group; however, experienced a significant decrease in anxiety scores with this reduction maintained at six and twelve-months post-intervention (Stapleton et al., 2017). These results suggest that EFT was more effective at impacting the symptoms of anxiety than the CBT treatment. The CBT group had higher self-reported depression scores than the EFT group prior to treatment, yet did not experience any reduction in those scores following the CBT treatment. The EFT group however, reported significant decreases in their depression symptoms immediately after intervention and after six- and twelve-months (Stapleton et al., 2017).

\subsection{Online or Web-Based Clinical Interventions}

Mounting evidence for the efficacy of online psychological treatments suggests 
that telehealth services will provide a low-cost solution to overcome barriers to treatment for those in remote and regional locations (Barak, Hen, Boniel-Nissim, \& Shapira, 2008). As well as reducing costs for health care providers, online psychological therapies may have advantages over in person therapies for certain psychological issues (Hedman et al., 2014). Internet based treatment has proven an effective format for some anxiety disorders where the psychological disorder itself is a barrier for seeking treatment, such as social anxiety or agoraphobia (Berger, Boettcher, \& Caspar, 2014). Online therapy is relatively anonymous, carries less stigma and many patients find it easier to confide more difficult problems in an online format (Spek et al., 2007).

\subsection{Online EFT for Food Cravings}

One study examined a six-week EFT online program for food cravings (Church \& Wilde, 2013). Participants lost weight within the six-week program with average weight loss around 5.4 kilograms, additionally reporting a reduction in self-reported levels of depression (Church \& Wilde, 2013). A similar program examined the effectiveness of EFT for both weight loss and symptoms of PTSD (Church, Stapleton, Sheppard, \& Carter, 2018) and while online delivery of EFT for weight loss overall was positive, neither studies included a control or comparison group.

Most recently, a worldwide study of 314 adults randomly allocated obese or overweight adults to a treatment group or waitlist condition $(n=254)$, to further investigate the online form of EFT. This study took the existing 8-week EFT program from previous in-person research, and organised it into an online version. In the online RCT, participants completed an 8-week online EFT intervention through 32 video sessions across seven modules targeting the same variables identified in prior in-person research: food cravings, dietary restraint, the subjective power of food, BMI, somatic symptom severity, anxiety, and depressive symptoms.

The course content was identical to the material delivered in prior in-person sessions and participants were able to access their weekly material multiple times. They were provided access to an online group where the lead therapist was available for real time support. Significant reductions were observed across all measures for participants in the EFT condition, with no significant differences observed for participants in the waitlist condition. Once the waitlist had also completed the program, the groups were collapsed for analysis and results revealed significant reductions from pre to post-treatment scores across all measures, that was maintained at the six and twelve month follow up (Stapleton, Roos, Mackintosh, Sparenburg \& Carter, 2019). The sample was contacted for two-year follow-up and further improvements were experienced for carbohydrates and fast food cravings between 6 months and 2 years (Stapleton, Lilley-Hale, Mackintosh, \& Sparenburg, 2019). This research represents the first clinically researched study into the online delivery of EFT for weight manage- 
ment including a two-year follow-up period, and suggests that online EFT may have clinical utility as a tool to assist in targeting the obesity, although to date no research has compared the efficacy of online versus in-person. EFT has demonstrated efficacy in reducing food cravings and addressing weight and food related behaviours in adult populations, as well as reducing anxiety, depression and somatic symptoms (Stapleton et al., 2016, 2017). Prior research has supported the effectiveness of EFT utilising both online and in-person formats; however, no research has yet sought to compare these treatment modalities. The current study, therefore, sought to compare the effectiveness of an eight-week online mode of therapy with an eight-week in-person format to support the clinical utility of this approach for rural and remote populations.

\section{Method}

\subsection{Participants}

The two original studies received ethics approval from the University Human Research Ethics Committee and both were registered under the Australia New Zealand Clinical Trials Registry.

For each study a purposive sample of participants was recruited using a variety of print advertising, radio and television community announcements. Participants were required to meet a set of eligibility criteria including being male or female, 18 years or older and not be currently diagnosed with any severe psychological issues nor receiving treatment, psychological or medical, for their food cravings. All participants were required to be currently experiencing daily food cravings and asked to participate in follow up data collection. Exclusion criteria included past or present sufferers of anorexia or bulimia nervosa, as well as pregnancy or diabetes type I and II, or hypoglycaemia to prevent such physiological effects confounding the data.

\subsection{Study One: In-Person}

The first study attracted 207 potential candidates from the community and 177 were screened for eligibility via telephone interview on a first come first serve basis (see Figure 2 for Consort Diagram). An additional screening tool was utilised in this study to ensure that participants did not meet criteria for psychological disorders. The Symptom Assessment 45 (SA-45; Strategic Advantages 2000) is a brief, psychometrically sound instrument designed to screen for the presence of psychiatric diagnoses. Participants who met the screening criteria for any psychiatric disorder on the SA-45 were excluded from the sample. For this study participants were required to have a BMI above 25 and be in the overweight or obese category. Of the 177 participants screened, 37 declined to participate and 57 did not meet the eligibility criteria and the remaining 83 participants were randomised into either an eight-week EFT treatment or an eight-week CBT group with 51 participants finalised for the EFT treatment and 32 for the CBT group. A power analysis was run to determine the minimum 


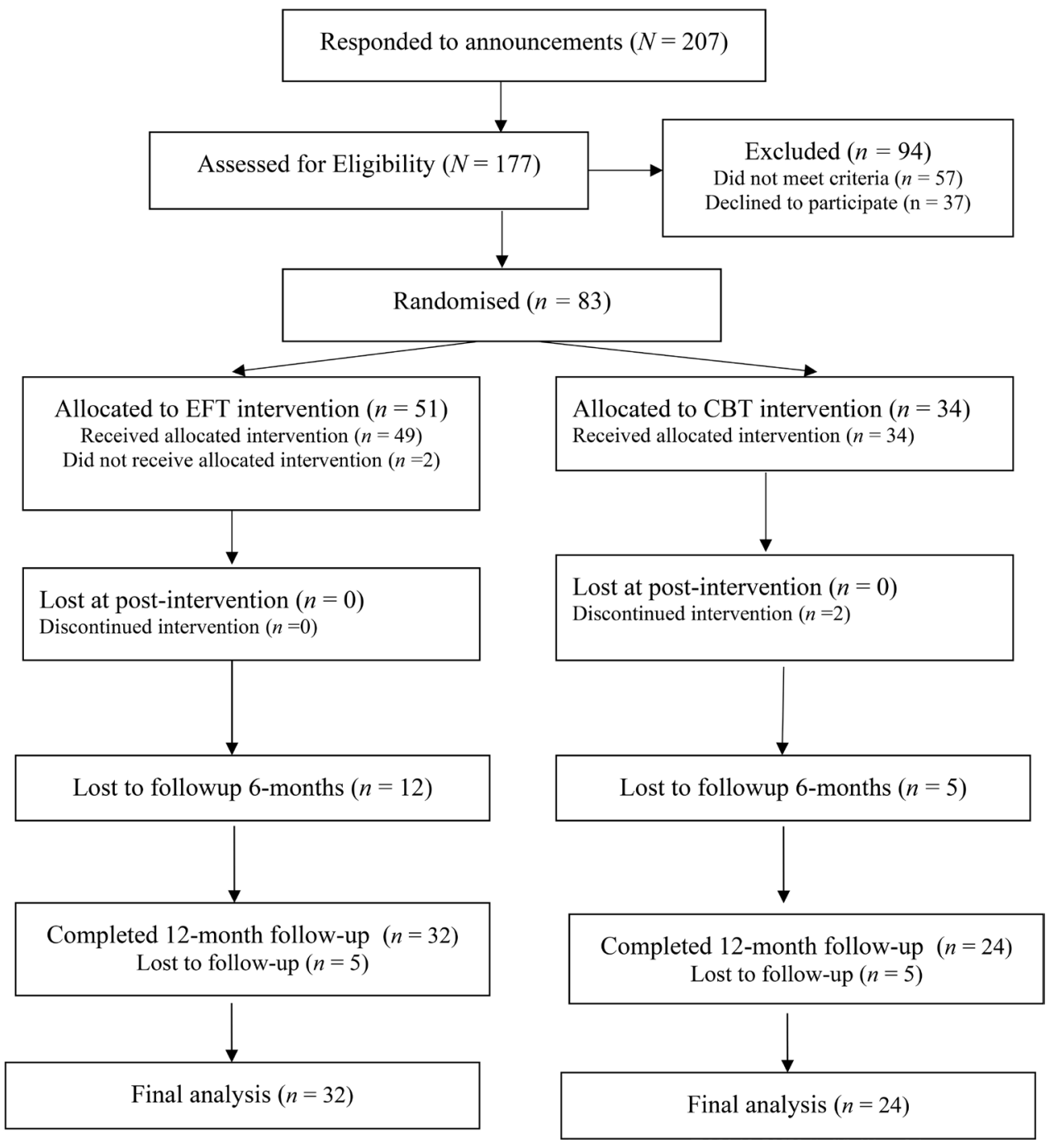

Figure 2. Consort diagram of in-person study.

group size and it was determined that each group required 34 participants to detect a medium effect size with 87 per cent power $(\alpha=.05)$. A final group of 49 participants received the EFT intervention, with all 49 completing the pre and post intervention questionnaires (note: the CBT results are not discussed here).

\subsection{Study Two: Online Group}

For the worldwide, self-paced online program $G^{*}$ Power analysis indicated a minimum number of participants of 122 . The final sample (excluding waitlist condition) comprised 314 participants residing across multiple locations globally (see Figure 3 for Consort Diagram).

\subsection{Measures}

The same measures were implemented for the in-person and online studies, except in the online study psychological variables were measured purely by the Patient Health Questionnaire (PHQ; Spitzer, Kroenke, \& Williams, 1999) and the 


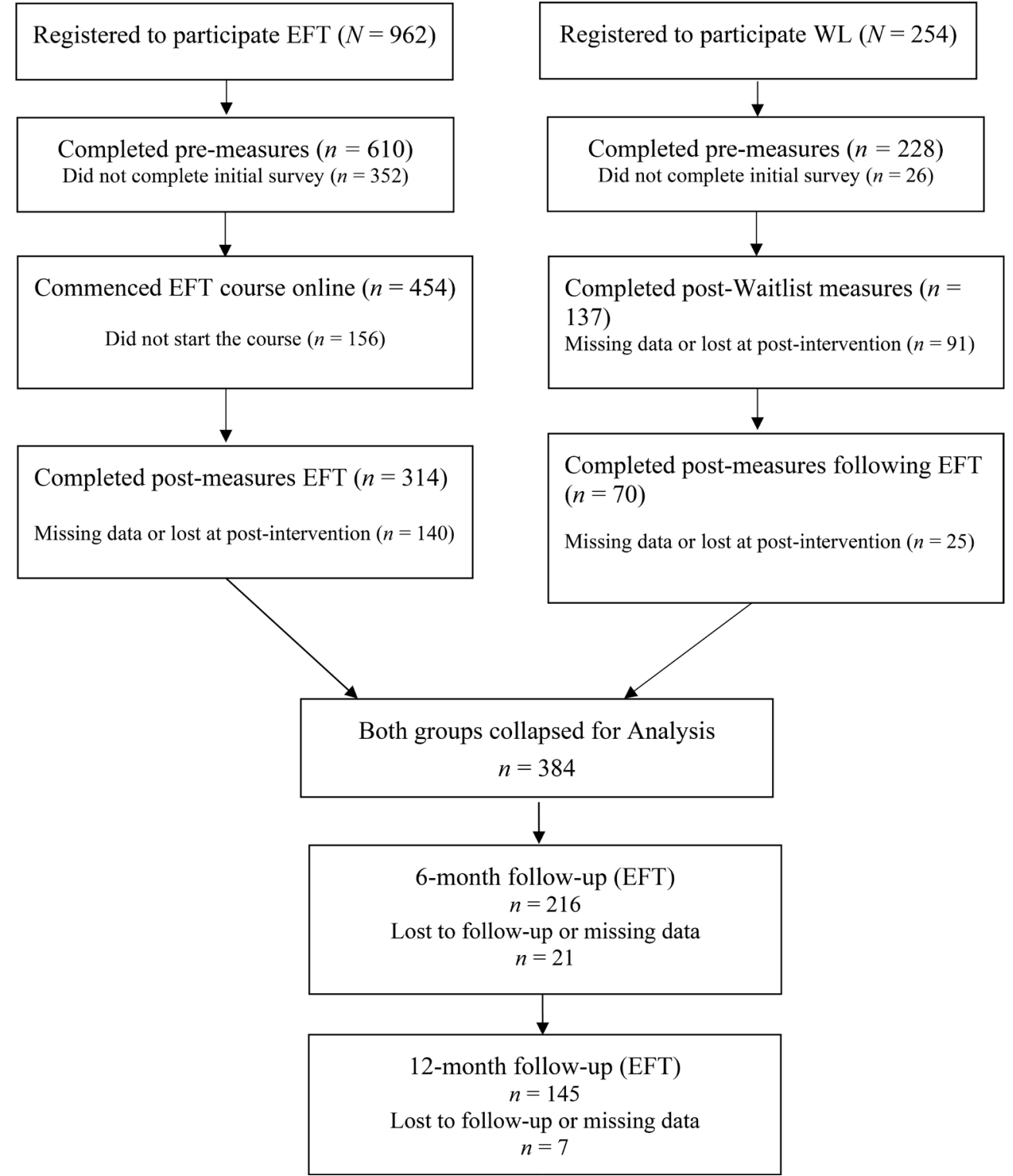

Figure 3. Consort diagram of online study.

additional psychological screening process utilising the SA-45 was omitted.

\subsubsection{Anthropometric Measures}

BMI was calculated using the height and weight of each participants using the formula weight in kilograms divided by height in metres squared $\left(\mathrm{kg} / \mathrm{m}^{3}\right)$. Using BMI the participants were categorised into healthy weight (18.5 - 24.9) overweight $(25.0-29.9)$ or obese $(\geq 30.0)$. Participants defined as underweight $(<18.5)$ or were excluded.

\subsubsection{Food Craving Inventory}

The Food Craving Inventory (FCI; White et al., 2002) is a 37-item self-report inventory that measures cravings for 37 specific foods across a 30-day time frame. Craving is defined as an intense desire for a specific food that is difficult 
to resist. Participants use a 5-point Likert scale ranging from 0 ("never") to 4 ("always/almost every day") to rate their subjective level of craving for each food item over the past month. Scores for the inventory range from 0 to a maximum of 148 with higher scores reflecting more intense experiences of food cravings. The FCI contains four subscales however only the total score was utilised. The FCI has demonstrated validity and reliability with internal consistency scores for the subscales ranging from .70 for fast food fats to .86 for sweets, and Cronbach's alphas for the total instrument demonstrate internal consistency ranges from .86 to .93 (White \& Grilo, 2005; White et al., 2002).

\subsubsection{Power of Food Scale}

The Power of Food Scale (PFS; Lowe et al., 2009) is a 21-item, self-report instrument, devised to measure the impact of living in environments containing abundance of highly palatable foods and directly measures the anticipation of these foods, rather than consumption (Lowe et al., 2009). Items are rated on a five-point Likert scale from 1 (do not agree at all) to 5 (strongly agree) with a minimum score of 21 and a maximum score of 105 with high scores indicating greater levels of responsiveness to palatable foods in the environment (Lowe et al., 2009).

\subsubsection{Revised Restraint Eating Scale}

The Revised Restraint Eating Scale (RRS; Herman \& Polivy, 1980) is a 10-item self-report assessment that measures an individual's behaviour and attitude in relation to dieting and weight control (Provencher, Polivy, \& Herman, 2009). Each question is answered on a four or five point Likert scale with total scores range from 0 to 35 . Higher scores indicate a greater degree of dietary restraint (a tendency at times to severely restrict calorie intake, and at other time ingest calories excessively; Laessle et al., 1989). Lower scores on the RRS indicate low restraint which is characteristic of persons with more internal regulation of food intake, while higher scores indicate individuals that are externally regulated with higher tendency to respond to food cues in their environment. The RRS is a psychometrically sound and valid measure that demonstrates good internal consistency (Laessle et al., 1989; Tiggemann \& Kemps, 2005).

\subsubsection{Patient Health Questionnaire}

The Patient Health Questionnaire (PHQ; Spitzer et al., 1999) is a self-report inventory that has clinical utility as a screening tool for depression, anxiety, eating disorders, alcohol use and somatoform disorders. For the current study the subscales for depression, anxiety, and somatoform were used. For the somatoform module, participants were required indicate how bothered they had been by various physiological complaints over the preceding 4-week period, on a 3-point scale ranging from $0=$ Not bothered to $2=$ Bothered a lot. Sample items were "Pain in your arms, legs, or joints" and "Constipation, loose bowels, or diarrhea". Total scores of 5, 10, and 15 represent cut-off points for low, medium, and high somatic symptom severity, respectively. For the depression module, par- 
ticipants were required to indicate often they had been bothered by various depressive symptoms over the preceding 2-week period, on a 4-point scale ranging from $0=$ Not at all to $3=$ Nearly every day. Sample items were "Little interest or pleasure in doing things" and "Trouble concentrating on things, such as reading the newspaper or watching television". Total scores of 5, 10, 15, and 20 represent cut-off points for mild, moderate, moderately severe, and severe depression, respectively. For the anxiety module, participants were required to indicate how often they had been bothered by various anxiety symptoms over the preceding 4 -week period, on a 3-point scale ranging from $0=$ Not at all to $2=$ More than half the days. Sample items were "Feeling restless so that it is hard to sit still" and "Trouble falling asleep or staying asleep". Total scores of 5, 10, and 15 represent cut-off points for mild, moderate, and severe anxiety, respectively. Each subscale has high internal consistency $(\alpha>.85)$ and the PHQ scale has excellent test-retest reliability $(r>.80$; Kroenke, Spitzer, \& Williams, 2001; Kroenke, Spitzer, \& Williams, 2002).

\subsection{Treatment Conditions}

\subsubsection{In-Person Treatment Intervention}

The interventions for the in-person treatment condition consisted of eight two-hour sessions conducted weekly between 2012 and 2014 and administered by trained Clinical EFT facilitators. Participants were provided weekly handouts covering a range of topics including psychoeducational components and were taught to apply EFT to their food cravings through exposure exercises. An EFT set up and acceptance phrase was adapted for the client's needs and type of food craved, for example, for cake the set up phrase was "Even though I have this craving for this cake, I accept myself anyway". The individual then tapped through the points using the shortened reminder phrase (e.g. this craving) and tuned into the experience of the craving in real time (Craig, 2010). Aspects of the craving that emerged during the tapping sequence were then addressed, for example, any emotions that surfaced were addressed through a new set up statement and further rounds of tapping (e.g. sadness, deprivation; Craig, 2010). Clients were encouraged to use their tapping outside of sessions, for example whenever they noticed an experience of food craving, or the associated emotions.

\subsubsection{Online Treatment Intervention}

The online treatment condition consisted of the same material as the in-person program with the eight two-hour sessions split into 65 online modules designed to be accessed over eight weeks. Each week's content was released weekly to ensure no participants could skip ahead. Modules were conducted in the same way as the in-person training and was facilitated with segments recorded by an experienced Clinical EFT facilitator (the lead author). To ensure participants did not skip parts of the training, and that it was delivered in the same order as the in-person condition, a brief multiple choice test was provided at the end of each 
segment. Participants were required to answer these questions in order to gain access to the next segment. Clients were provided the same weekly handouts as utilised in the in-person treatment and while their program was self-paced over the eight-week period, it was supported with an online secret Facebook group, which participants could join if they wished. The lead researchers and facilitators were part of this group and available for support and to answer any questions during the trial.

\section{Results}

\subsection{Data Diagnostics}

Data analysis was performed using IBM Statistical Package for Social Sciences (SPSS) Version 24. An alpha level of .05 was implemented to detect statistically significant results. Overall the data was deemed to meet the requirements for the assumption of normal distribution.

A power analysis was executed using $\mathrm{G}^{*}$ Power (Faul, Erdfelder, Lang, \& Buchner, 2007) indicating that a minimum sample of 138 was required to find an effect size of 0.25 within the current analysis. The final sample size consisted of 363 participants (314 online, 49 in person), with 154 of these participants providing data across the four time points for the main variables of interest; food cravings, power of food and restraint, therefore the final sample size was deemed to have sufficient power to complete the statistical analysis. The final sample sizes for participants providing data across all four time points varied across the secondary variables of interest with 145 for weight, 144 for BMI, 153 for depression, 152 for somatic symptoms and 61 for anxiety.

Chi-square analyses were used to determine if demographic characteristics differed between the online and in-person groups prior to the intervention. Results of the chi-square test for age revealed that there was a between groups difference across the variable of age category $\left(\chi^{2}(8, N=356)=29.89, p<.001\right)$. Further inspection of the results indicated that those aged under 40 made up a higher proportion of the online group, then the in-person group. This did not present a problem as the difference between expected count and observed count was minimal.

Results of the chi-square for gender indicated a between groups difference with slightly more males as a proportion of the in-person group, compared to the on-line group, $\chi^{2}(1, N=363)=6.38$, and was significant based on Fisher's exact test, $p=.023$. This did not present a problem as males were generally underrepresented across both groups therefore the results are not generalizable to males (see Table 1). Analysis of the attrition data for the participants indicated that the attrition rate did not differ at the six month follow up, $\left(\chi^{2}(1, N=363)\right.$ $=.24, p=.63)$, nor at the twelve month follow up between treatment groups $\left(\chi^{2}\right.$ $(1, N=363)=2.04, p=.15)$. This suggested that there were no between group differences in the percentages of attrition across the four time points. Further analyses for between group differences using Fisher's exact test revealed a 
Table 1. Summary of demographic information.

\begin{tabular}{|c|c|c|}
\hline Variable & Online $(n=314)$ & In Person $(n=49)$ \\
\hline \multicolumn{3}{|l|}{ Gender } \\
\hline Female & $302(96 \%)$ & $43(88 \%)$ \\
\hline Male & $12(4 \%)$ & $6(12 \%)$ \\
\hline \multicolumn{3}{|l|}{ Age } \\
\hline$\leq 25$ years & $3(1 \%)$ & $4(8 \%)$ \\
\hline 26 to 30 years & $4(1 \%)$ & $4(8 \%)$ \\
\hline 31 to 40 years & $37(12 \%)$ & $12(25 \%)$ \\
\hline 41 to 50 years & $92(30 \%)$ & $7(15 \%)$ \\
\hline 51 to 60 years & $103(34 \%)$ & $14(28 \%)$ \\
\hline$\geq 61$ years & $68(22 \%)$ & $8(16 \%)$ \\
\hline Mean BMI $(S D)$ & $33.3(6.52)$ & $33.1(6.52)$ \\
\hline Mean Weight (SD) & $89.98(18.52)$ & $90.60(19.83)$ \\
\hline Normal weight & $21(7 \%)$ & $2(4 \%)$ \\
\hline Overweight & $91(30 \%)$ & $13(27 \%)$ \\
\hline Class I BMI $30-34.99$ & $91(30 \%)$ & $16(32 \%)$ \\
\hline Class II BMI 35 - 39.99 & $52(17 \%)$ & $13(27 \%)$ \\
\hline Class III BMI 40+ & $50(16 \%)$ & $5(10 \%)$ \\
\hline Married & $166(54 \%)$ & $25(51 \%)$ \\
\hline Education post-secondary school & $266(86 \%)$ & $41(83.7 \%)$ \\
\hline Employed & $234(75 \%)$ & $30(61 \%)$ \\
\hline Mean Somatic (SD) & $7.52(4.32)$ & $8.59(3.57)$ \\
\hline Mean Depression (SD) & $9.12(5.87)$ & $8.61(6.73)$ \\
\hline Mean Anxiety (SD) & $7.15(3.32)$ & $4.93(4.60)$ \\
\hline \multicolumn{3}{|l|}{ Income (AUD\$) } \\
\hline$<\$ 10,000$ & $4(1 \%)$ & $11(23 \%)$ \\
\hline$\$ 10,001$ to $\$ 40,000$ & $60(20 \%)$ & $14(28 \%)$ \\
\hline$\$ 40,001$ to $\$ 60,000$ & $62(21 \%)$ & $7(15 \%)$ \\
\hline$\$ 60,001$ to $\$ 80,000$ & $44(15 \%)$ & $3(6 \%)$ \\
\hline$\$ 80,001$ to $\$ 100,000$ & $52(17 \%)$ & $5(10 \%)$ \\
\hline$>\$ 100,000$ & $82(27 \%)$ & $9(18 \%)$ \\
\hline
\end{tabular}

significant difference between groups based on marital status $\left(\chi^{2}(6, N=356)=\right.$ 12.44, $p=036)$ and type of food craved $\left(\chi^{2}(6, N=363)=36.53, p<.001\right)$.

A series of independent samples $t$-tests on pre-intervention data indicated no significant differences for BMI $(p=.851)$, or weight $(p=.385)$. However, there was a difference between weight at baseline between completers and non-completers in the online group. Baseline weight at pre-intervention for the 119 online participants who completed all follow ups was lower $(M=85.82 \mathrm{~kg})$ than online non-completers $(N=190 ; M=92.59 \mathrm{~kg})$ with a significant difference observed between online completers and non-completers $(t(307)=3.18, p=.002)$. Inde- 
pendent samples $t$-tests on baseline measures revealed no significant differences between groups (online versus in-person) across somatic symptoms $(p=.11)$ and depression $(p=.580)$. Participants in both treatment conditions exhibited baseline depression and somatic symptoms in the mild range. A significant between groups difference was observed for anxiety $(t(291)=17.82, p<.001)$ with online participants experiencing higher levels of anxiety $(M=7.39, S D=2.67)$ than in-person participants $(M=5.21, S D=4.18)$.

Independent samples $t$-tests were run on baseline measures to detect between groups differences (online versus in-person) for food cravings, power of food and restraint to check for between groups differences between online and in-person. Results were non-significant for power of food $(p=.18)$ and restraint $(p=.77)$; however, for food cravings there was a significant between group difference $(t(361)=5.97, p<.001)$. The $t$-tests were repeated using equal group sizes with results not differing meaningfully, thus suggesting that the between group differences for food cravings was not an artefact of unequal groups sizes (Tabachnick \& Fidell, 2013). The online treatment group had significantly higher scores for food cravings than the in-person group (see Table 2). The between groups differences for food cravings did not present an issue as there was no interaction between the variable of time and treatment condition.

The number of online participants completing the anxiety measure was drastically lower than all other measures $(n=33)$. A series of $t$-tests were conducted between the 61 participants from both the in-person and online groups, who had completed all four anxiety measures, and the 305 participants who had not

Table 2. Means and standard deviations for all variables at all four time points (participants who completed all follow ups).

\begin{tabular}{|c|c|c|c|c|c|c|c|c|c|c|c|c|}
\hline \multirow[b]{2}{*}{ Variable } & \multicolumn{4}{|c|}{ In Person $(n=28)$} & \multicolumn{4}{|c|}{ Online $(n=128)$} & \multicolumn{4}{|c|}{ Combined Groups } \\
\hline & $\begin{array}{c}\text { Pre } \\
M(S D)\end{array}$ & $\begin{array}{c}\text { Post } \\
M(S D)\end{array}$ & $\begin{array}{c}6 \text { Month } \\
M(S D)\end{array}$ & $\begin{array}{l}12 \text { month } \\
M(S D)\end{array}$ & $\begin{array}{c}\text { Pre } \\
M(S D)\end{array}$ & $\begin{array}{c}\text { Post } \\
M(S D)\end{array}$ & $\begin{array}{c}6 \text { Month } \\
M(S D)\end{array}$ & $\begin{array}{c}12 \text { Month } \\
M(S D)\end{array}$ & $\begin{array}{c}\text { Pre } \\
M(S D)\end{array}$ & $\begin{array}{c}\text { Post } \\
M(S D)\end{array}$ & $\begin{array}{c}6 \text { Month } \\
M(S D)\end{array}$ & $\begin{array}{c}12 \text { Month } \\
M(S D)\end{array}$ \\
\hline $\begin{array}{c}\text { Food } \\
\text { Craving }\end{array}$ & $\begin{array}{c}61.68 \\
(20.52)\end{array}$ & $\begin{array}{c}48.57 \\
(13.65)\end{array}$ & $\begin{array}{c}48.39 \\
(12.33)\end{array}$ & $\begin{array}{c}51.75 \\
(14.43)\end{array}$ & $\begin{array}{c}81.00 \\
(18.75)\end{array}$ & $\begin{array}{c}62.48 \\
(20.52)\end{array}$ & $\begin{array}{c}62.46 \\
(15.74)\end{array}$ & $\begin{array}{c}62.05 \\
(17.06)\end{array}$ & $\begin{array}{c}77.49 \\
(20.44)\end{array}$ & $\begin{array}{c}59.95 \\
(15.61)\end{array}$ & $\begin{array}{c}59.90 \\
(16.09)\end{array}$ & $\begin{array}{c}60.17 \\
(17.04)\end{array}$ \\
\hline $\begin{array}{c}\text { Power of } \\
\text { Food }\end{array}$ & $\begin{array}{c}70.43 \\
(21.31)\end{array}$ & $\begin{array}{c}53.32 \\
(21.37)\end{array}$ & $\begin{array}{c}49.39 \\
(27.06)\end{array}$ & $\begin{array}{l}51.29 \\
(22.86\end{array}$ & $\begin{array}{c}71.48 \\
(18.05)\end{array}$ & $\begin{array}{c}54.80 \\
(18.53)\end{array}$ & $\begin{array}{c}51.52 \\
(19.64)\end{array}$ & $\begin{array}{c}52.27 \\
(20.23)\end{array}$ & $\begin{array}{c}71.29 \\
(18.61)\end{array}$ & $\begin{array}{c}54.53 \\
(19.01)\end{array}$ & $\begin{array}{c}51.14 \\
(21.09)\end{array}$ & $\begin{array}{l}52.09 \\
(20.56)\end{array}$ \\
\hline Restraint & $\begin{array}{l}33.18 \\
(6.28)\end{array}$ & $\begin{array}{l}31.50 \\
(5.61)\end{array}$ & $\begin{array}{l}28.50 \\
(9.37)\end{array}$ & $\begin{array}{c}24.07 \\
(11.84)\end{array}$ & $\begin{array}{l}32.95 \\
(4.71)\end{array}$ & $\begin{array}{l}30.63 \\
(5.05)\end{array}$ & $\begin{array}{l}29.60 \\
(5.59)\end{array}$ & $\begin{array}{l}29.33 \\
(5.89)\end{array}$ & $\begin{array}{l}32.99 \\
(5.01)\end{array}$ & $\begin{array}{l}30.79 \\
(5.15)\end{array}$ & $\begin{array}{l}29.40 \\
(6.43)\end{array}$ & $\begin{array}{l}28.37 \\
(7.57)\end{array}$ \\
\hline Somatic & $\begin{array}{c}7.56 \\
(3.29)\end{array}$ & $\begin{array}{c}6.04 \\
(3.58)\end{array}$ & $\begin{array}{c}7.77 \\
(6.73)\end{array}$ & $\begin{array}{c}6.29 \\
(4.68)\end{array}$ & $\begin{array}{c}7.33 \\
(4.61)\end{array}$ & $\begin{array}{c}5.52 \\
(3.34)\end{array}$ & $\begin{array}{c}5.11 \\
(3.57)\end{array}$ & $\begin{array}{c}5.02 \\
(3.40)\end{array}$ & $\begin{array}{c}7.37 \\
(4.39)\end{array}$ & $\begin{array}{c}5.61 \\
(3.37)\end{array}$ & $\begin{array}{c}5.59 \\
(4.40)\end{array}$ & $\begin{array}{c}5.25 \\
(3.67)\end{array}$ \\
\hline Depression & $\begin{array}{c}8.00 \\
(6.35)\end{array}$ & $\begin{array}{c}5.50 \\
(3.83)\end{array}$ & $\begin{array}{c}5.11 \\
(5.58)\end{array}$ & $\begin{array}{c}6.25 \\
(7.28)\end{array}$ & $\begin{array}{c}7.63 \\
(4.99)\end{array}$ & $\begin{array}{c}5.04 \\
(4.22)\end{array}$ & $\begin{array}{c}5.29 \\
(4.80)\end{array}$ & $\begin{array}{c}5.65 \\
(4.89)\end{array}$ & $\begin{array}{c}7.70 \\
(5.25)\end{array}$ & $\begin{array}{c}5.13 \\
(4.15)\end{array}$ & $\begin{array}{c}5.25 \\
(4.93)\end{array}$ & $\begin{array}{c}5.76 \\
(5.38)\end{array}$ \\
\hline Anxiety & $\begin{array}{c}5.21 \\
(4.18)\end{array}$ & $\begin{array}{c}5.86 \\
(3.89)\end{array}$ & $\begin{array}{c}3.14 \\
(4.78)\end{array}$ & $\begin{array}{c}2.46 \\
(3.53)\end{array}$ & $\begin{array}{c}7.39 \\
(2.67)\end{array}$ & $\begin{array}{c}5.55 \\
(2.69)\end{array}$ & $\begin{array}{c}5.45 \\
(2.51)\end{array}$ & $\begin{array}{c}4.00 \\
(2.44)\end{array}$ & $\begin{array}{c}6.39 \\
(3.58)\end{array}$ & $\begin{array}{c}5.69 \\
(3.27)\end{array}$ & $\begin{array}{c}4.39 \\
(3.93)\end{array}$ & $\begin{array}{c}3.30 \\
(3.07)\end{array}$ \\
\hline Weight & $\begin{array}{c}90.72 \\
(21.16)\end{array}$ & $\begin{array}{c}90.56 \\
(20.83)\end{array}$ & $\begin{array}{c}86.80 \\
(20.89)\end{array}$ & $\begin{array}{c}86.89 \\
(20.87)\end{array}$ & $\begin{array}{c}85.82 \\
(16.96)\end{array}$ & $\begin{array}{c}84.75 \\
(17.26)\end{array}$ & $\begin{array}{c}84.23 \\
(16.49)\end{array}$ & $\begin{array}{c}83.43 \\
(15.82)\end{array}$ & $\begin{array}{c}86.72 \\
(19.83)\end{array}$ & $\begin{array}{c}85.82 \\
(18.03)\end{array}$ & $\begin{array}{c}84.72 \\
(17.31)\end{array}$ & $\begin{array}{c}84.07 \\
(16.84)\end{array}$ \\
\hline BMI & $\begin{array}{l}33.43 \\
(7.33)\end{array}$ & $\begin{array}{l}33.07 \\
(7.30)\end{array}$ & $\begin{array}{l}31.35 \\
(7.51)\end{array}$ & $\begin{array}{l}31.36 \\
(7.75)\end{array}$ & $\begin{array}{l}31.73 \\
(5.67)\end{array}$ & $\begin{array}{l}31.34 \\
(5.81)\end{array}$ & $\begin{array}{l}31.15 \\
(7.51)\end{array}$ & $\begin{array}{l}30.87 \\
(5.45)\end{array}$ & $\begin{array}{l}32.05 \\
(6.02)\end{array}$ & $\begin{array}{l}31.66 \\
(6.02)\end{array}$ & $\begin{array}{l}31.19 \\
(5.94)\end{array}$ & $\begin{array}{l}30.96 \\
(5.92)\end{array}$ \\
\hline
\end{tabular}


completed all four anxiety measures. Results indicated no between groups differences on baseline measures between anxiety completers and non-completers for the following: power of food $(p=.359)$, restraint $(p=.595)$, somatic symptoms $(p=.597)$, depression $(p=.967)$, anxiety $(p=.356)$, weight $(p=.506)$, or BMI $(p=.151)$. A difference was detected between anxiety completers and non-completers for food cravings $(t(361)=2.39, p=.043)$. Anxiety completers having lower food cravings $(M=75.57, S D=22.36)$ than anxiety non-completers $(M=81.41, S D=20.12)$.

To further investigate attrition a series of $t$-tests were run on baseline measures to investigate differences between completers and non-completers. For the in-person group, results indicated no significant differences across baseline measures: food cravings $(p=.239)$, power of food $(p=.447)$, restraint $(p=.894)$, somatic symptoms $(p=.245)$, depression $(p=.468)$, anxiety $(p=.633)$, weight $(p=.834)$ and BMI $(p=.734)$. For the online group there were no significant differences observed at baseline between completers and non-completers for food cravings $(p=.165)$, power of food $(p=.565)$, restraint $(p=.104)$, or somatic symptoms $(p=.524)$. There were significant differences between observed at baseline for depression $(t(299.17)=.638, p<.001)$, anxiety $(t(242)=2.31 p$ $=.022)$, weight $(t(307)=3.17, p=.002)$ and BMI $(t(302)=3.18, p=.002)$. In the online condition the non-completers reported higher levels of anxiety $(M=$ 7.53, $S D=3.42)$, depression $(M=10.12, S D=6.20)$, weight $(M=92.59 S D=$ $19.01)$ and BMI $(M=34.02, S D=6.49)$, than the completers (anxiety $M=6.54$, $S D=3.09$; depression $M=7.63, S D=5.00$; weight $M=85.82 S D=16.96$; BMI $M$ $=31.73, S D=5.67)$.

\subsection{Main Analysis}

Eight mixed factorial repeated measures ANOVAs (food cravings, power of food, restraint, anxiety, depression, somatic symptoms, BMI and weight) were conducted to determine whether there were statistically significant differences ( $p$ $<.05$ ) between in-person and online treatment groups following an eight-week intervention across four time points (pre, post, six-month and twelve-month).

Levene's test indicated that the assumption of homogeneity of variance was met for food cravings, weight and BMI; however, it was violated for power of food, restraint, somatic symptoms, depression and anxiety. In each case of a violation the ANOVA was repeated with equal groups by selecting a random sample from the online group equal in size to the in-person group (Stevens, 2002).

In sum, both modalities were comparable in efficacy and experienced significant reductions from pre-intervention to post-intervention, with reductions remaining significant at follow ups for food cravings, power of food, depression and weight, with minor differences observed at post-intervention or 6-month follow up for dietary restraint, somatic symptoms, anxiety and body mass index. Follow-up analyses revealed a significant effect of depression, anxiety and weight on attrition in the online treatment group. Each are now outlined in depth. 


\subsubsection{Food Cravings}

Mauchly's test of sphericity indicated that the assumption of sphericity had been violated, $\chi^{2}(5)=40.00, p<.001$, therefore a Greenhouse-Geisser correction was applied $(\varepsilon=0.842)$. The mixed factorial ANOVA revealed a significant main effect for Time, $F(2.53,383.89)=42.61, p<.001$, partial $\eta^{2}=.22$. A priori pairwise comparisons across both groups conducted with a Sidak correction revealed that food cravings decreased from pre-intervention. There were significant between-group differences prior to the intervention, which remained consistent after treatment $\left(F(1,152)=27.07, p<.001\right.$, partial $\left.\eta^{2}=.15\right)$; however, no interaction was found between time and treatment condition $F(2.53,383.89)=2.49$, $p=.072$, partial $\eta^{2}=.016$. Pairwise comparisons indicated a significant decrease for food cravings pre and post $(p<.001)$, being maintained at the six and twelve month follow ups.

Combined groups experienced a $23 \%$ reduction in food cravings (see Table 2) from pre-intervention to post intervention, which remained consistent at the 12 month follow up.

\subsubsection{Power of Food}

Mauchly's test indicated that the assumption of sphericity had been violated, $\chi^{2}$ $(5)=23.037, p<.001$, therefore a Greenhouse-Geisser correction was applied $(\varepsilon$ $=0.910)$. The mixed factorial ANOVA revealed a significant main effect for Time, $F(2.73,415.15)=50.49, p<.001$, partial $\eta^{2}=.25$. Pairwise comparisons revealed significant reductions pre- to post-treatment $(p<.001)$ and remained stable from post-intervention to both 6 - and 12-months. Scores from post- to 6and 12-months were not significantly reduced, nor between 6 and 12 months $F$ $(1,152)=.17, p=.683$. No interaction was found between Time and Treatment Condition $F(2.73,415.15)=.038, p=.986$.

Combined groups experienced a $23.5 \%$ reduction in power of food from pre-intervention to post intervention, increasing to an overall $27 \%$ reduction from pre-intervention to 12 months.

\subsubsection{Restraint}

Mauchly's test revealed that the assumption of sphericity had been violated, $\chi^{2}$ $(5)=64.801, p<.001$, therefore, a Greenhouse-Geisser correction was applied $(\varepsilon$ $=0.782)$. The mixed factorial ANOVA revealed a significant main effect of Time, $F(2.35,356.72)=42.06, p<.001$, partial $\eta^{2}=.22$. Pairwise comparisons revealed scores had significantly improved pre- to post-intervention $(p<.001)$ and continued to improve from post to 6 months $(\mathrm{p}=.003)$, and from 6 months to 12 months $(p<.001)$. No significant main effect of treatment condition was observed, $F(1,152)=1.62, p=.206$. A significant interaction was found between Time and Treatment Condition, $F(2.35,356.72)=10.70, p<.001$, partial $\eta^{2}$ $=.07$. For the equal sized groups ANOVA the interaction effect between Time and Treatment condition became non-significant due to the lack of power ( $p$ $=.084)$. Post hoc analysis of the unequal groups significant interaction investi- 
gated the differences between the groups at each time point to determine at what point across the four time points the groups differed. The groups did not differ at pre, post or at the six-month time point; however, at twelve-months the online group scores stabilised, while the in-person group scores continued to decline.

Combined groups experienced a $6 \%$ improvement in restraint from pre-intervention to post intervention, with an overall $14 \%$ improvement observed from pre-intervention to 12 months.

\subsubsection{Somatic Symptoms}

Mauchly's test of sphericity indicated that the assumption of sphericity had been violated, $\chi^{2}(5)=27.724, p<.001$, therefore, a Greenhouse-Geisser correction was applied $(\varepsilon=0.904)$. The mixed factorial ANOVA revealed a significant main effect for Time, $F(2.71,406.95)=7.66, p<.001$, partial $\eta^{2}=.05$. Pairwise comparisons revealed that somatic symptoms were significantly lowered from pre- to post-intervention $(p<.001)$ and remained stable from post- to 6-months ( $p$ $=.128$ ); however, a statistically significant decrease was observed between 6 - to 12 -months $(p=.048)$. No significant main effect of treatment condition was observed, $F(1,150)=3.09, p=.081$. A significant interaction was found between Time and Treatment Condition, $F(2.71,406.95)=3.40, p=.021$, partial $\eta^{2}$ $=.022$. Post hoc analysis of the unequal groups significant interaction investigated the differences between the groups at each time point to determine at what point across the four time points the groups differed. The groups did not differ at pre, post or at the twelve-month time point; however, at six-months the online group scores remained lower than pre-intervention while the in-person group scores had increased to pre-intervention levels, before returning at 12-months to post-intervention levels. For the equal sized groups ANOVA the interaction effect between Time and Treatment condition disappeared due to the lack of power $(p=.080)$, and an effect of Treatment condition was observed, $F$ $(1,53)=5.59, p=.022$, partial $\eta^{2}=.10$.

Combined groups experienced a $23 \%$ reduction in somatic symptoms from pre-intervention to post intervention, with an overall $29 \%$ reduction from pre-intervention to 12 months.

\subsubsection{Depressive Symptomology}

The mixed factorial ANOVA revealed a significant main effect for Time, $F$ (3, $453)=10.99, p<.001$, partial $\eta^{2}=.07$. Pairwise comparisons revealed that depressive symptoms were significantly decreased from pre-intervention to immediately post-intervention, from pre-intervention to 6-months following intervention $(p<.001)$, and from pre-intervention to 12 months following intervention $(p=.001)$. There was no significant difference observed in participants' depressive symptomatology from post-intervention to either 6 months or 12 months, nor between 6 and 12 months. No significant main effect of treatment condition was observed, $F(1,151)=.14, p=.707$. No significant interaction was 
found between Time and Treatment Condition, $F(3,453)=0.21, p=.887$.

Combined groups experienced a $33 \%$ reduction in depressive symptoms from pre-intervention to post intervention, with an overall $25 \%$ reduction observed from pre-intervention to the 12 months.

\subsubsection{Anxious Symptomology}

The mixed factorial ANOVA revealed a significant main effect for Time, $F$ (3, $177)=17.331, p<.001$, partial $\eta^{2}=.23$. Pairwise comparisons revealed that anxious symptoms were not significantly decreased from pre- to post-intervention $(p=.137)$. However, there was a statistically significant difference observed in participants' depressive symptomatology from post- to 6-months $(p=.004)$, and between post- to 12-months' follow-up $(p<.001)$, and between the 6 and 12 month follow up $(p=.025)$. A significant main effect of treatment condition was observed, $F(1,59)=4.78, p=.033$, partial $\eta^{2}=.08$. A significant interaction was found between Time and Treatment Condition, $F(3,177)=3.30, p=.022$, partial $\eta^{2}=.05$. Preliminary analysis had highlighted the between groups difference of anxiety prior to the intervention; although, this does not explain the interaction. Post hoc analysis investigated the differences between groups at each time point revealed that the in-person group's anxiety was increased immediately post intervention, while for the online group it was reduced. The online group's scores then remained stable between post-intervention and 6 months, while between 6 and 12 months it reduced further. For the in-person group anxiety levels were reduced between post intervention and the 6 month follow up, and reduced even further by 12 months.

Combined groups experienced a $11 \%$ reduction in anxious symptoms from pre-intervention to post intervention, with an overall $48 \%$ reduction from pre-intervention to the 12 months.

\subsubsection{Weight}

For participants' weight, Mauchly's test indicated that the assumption of sphericity had been violated, $\chi^{2}(5)=152.60, p<.001$, therefore, a Greenhouse-Geisser correction was applied $(\varepsilon=.608)$. The mixed factorial ANOVA revealed a significant main effect for Time, $F(1.83,262.78)=12.13, p<.001$, partial $\eta^{2}=.08$. Pairwise comparisons revealed that between pre- and post-intervention there was no significant effect of treatment on weight $(p=.078)$. However, there was a significant difference between post-intervention scores and the 6-month follow $(p<.001)$, and between post intervention and-12 months $(p=.001)$. There was no significant difference between 6 and 12 months $(p=.488)$. There was no significant effect of Treatment Condition, $\mathrm{F}(1,144)=1.31, \mathrm{p}=.254)$. There was significant interaction observed between Time and Treatment Condition, $F$ $(1.83,262.76)=2.70, p=.074$.

Both groups combined experienced a $1 \%$ reduction in weight from pre to post intervention, and an overall reduction of $3 \%$ from pre-intervention to 12 months. 


\subsubsection{BMI}

Mauchly's test indicated that the assumption of sphericity had been violated, $\left(\chi^{2}\right.$ $(5)=142.85, p<.001)$, therefore a Greenhouse-Geisser correction was applied $(\varepsilon$ $=0.616)$. The mixed factorial ANOVA revealed a significant main effect of Time, $F(1.85,264.28)=18.11, p<.001$, partial $\eta^{2}=.11$. Pairwise comparisons revealed that BMI pre was statistically and significantly decreased at post $(p=.007)$; was significantly decreased between pre-intervention and 6 months $(p<.001)$, and between pre-intervention and 12 months $(p<.001)$. There was a significant reduction between post-intervention and 6 months $(p<.001)$ and between post-intervention and 12 months $(p<.001)$. There was no significant difference between 6 and 12 months $(p=.485)$. There was no significant main effect of Treatment Condition, $F(1,143)=0.68, p=.410$; however, there was a significant interaction observed between Time and Treatment Condition, $F(1.85,264.28)=$ 5.63, $p=.005$, partial $\eta^{2}=.04$. At the 6 and 12-month follow up the in-person groups' scores decline more dramatically than the online group scores suggesting that there was a greater impact on BMI for the in-person group than the online group.

Combined groups experienced a $1 \%$ reduction in BMI from pre-intervention to post intervention, with an overall reduction of $3.5 \%$ from pre-intervention to 12 months.

\section{Discussion}

Recent research has supported the application of a novel intervention, EFT, to address the internal psychological determinants affecting food choices and weight gain via an in-person format (Church \& Brooks, 2010; Stapleton, Sheldon, \& Porter, 2012; Stapleton, Bannatyne, Porter, Urzi, \& Sheldon, 2016), and more recently as an online intervention (Church \& Brooks, 2010; Church \& Wilde, 2013; Stapleton et al., 2012, 2016, 2019). To date no study has explored whether these two modalities are equivalent in efficacy, or whether an online or in-person mode of treatment is more efficacious than the other.

Despite a between groups difference for food cravings at pre-intervention, both groups experienced a similar reduction from pre to post intervention, which was maintained at the 6 and 12-month follow up and no interaction between groups was observed. Both groups experienced a significant reduction from pre to post-intervention, with these results remaining stable at the 6 and 12-month follow up. Dietary restraint scores improved from pre to post intervention, and continued to improve for both groups between post-intervention and 6 months and for the in-person group between 6 and 12 months.

Both groups also experienced a significant reduction in weight from pre to 6 months, and pre-intervention to 12 -months. The mean weight loss for the online group from pre-intervention to 12 months was 2.39 kilograms (1.5\%) while for the in-person group it was slightly higher at 3.83 kilograms (4\%). There were no significant between group differences in total weight lost, although the interac- 
tion was approaching significance $(p=.074)$ suggesting that with a larger sample size an interaction between treatment condition and time may have been observed.

The online and in-person groups achieved a significant effect of treatment; however, the results insinuate that there may be a stronger effect of treatment on weight for in-person therapy than for online therapy. Differences in weight between completers and non-completers within the online group indicated that the average weight at baseline of participants who did not complete all follow ups compared was 6.77 kilograms heavier than completers. These findings support research which suggests a relationship between weight and attrition (Teixeira et al., 2004).

For depression both groups experienced a significant effect of time with scores reducing from pre to post intervention and remaining stable at 6 and 12 months. For somatic symptoms both groups did experience an overall reduction in the level of symptoms by the 12 month follow up; however, the effect was different at 6 months when the in-person group experienced a rise in levels of symptoms, before they reduced again at 12 months. The online group experienced a greater overall reduction in somatic symptoms from pre-intervention to 12 months $(31.5 \%)$ than the in-person group (16\%).

For anxiety both groups experienced a decrease in symptoms from pre-intervention to the 6 and 12-month follow up; however, once again a differential effect across time was observed between groups. Symptoms of anxiety for the in-person group initially increased from pre intervention to post intervention before declining with an overall reduction of 53\% observed from baseline at the 12 month follow up. The online groups' scores decreased from pre to post intervention, remained stable at the 6-month follow up and continued to decline from 6 to 12 months with an overall reduction of $46 \%$ from baseline. The initial increase in anxiety at post-intervention for the in-person group could suggest that participating in an in-person treatment group can initially increase the experience of anxiety. This is consistent with research that suggests a particular benefit of online treatment for anxiety is the elimination of situational stress elicited by face-to-face interventions (Berger et al., 2014).

Results of the analysis between the completers and non-completers revealed a significant between groups difference in pre-intervention levels of depression and anxiety, which is consistent with existing research indicating a strong relationship between attrition, anxiety and depression (Fabricatore et al., 2009; Honas et al., 2003; McLean et al., 2016). The fact that this was only observed in the online group is compatible with studies that propose that the presence of anxiety and depression can cause higher rates of attrition for online therapy programs (Christensen et al., 2009). Differences between the non-completers in the online group on the variable of weight was also consistent with research suggesting that higher rates of obesity are correlated with increased likelihood of attrition, and increased likelihood of comorbid psychological disorders (Bodenlos et al., 2011; 
Gariepy et al., 2010; Luppino et al., 2010; McLean et al., 2016). These findings highlight the importance of identifying these high risk clients in order to offer targeted assistance for their depression and anxiety to enhance program adherence.

\section{Conclusion}

While this is the first study comparing online EFT with in-person EFT, replication studies using larger sample sizes, particularly for the in-person condition, are recommended. The current study had a low number of males, although the overrepresentation of females is consistent with research into emotional eating (Zellner et al., 2006). A further limitation is that the in-person group was selected under a specific exclusion criterion, while the online group participants self-selected their inclusion. The cost of in-person treatment often makes the selection process a necessary pre-requisite for admittance to an in-person program, while for an online program greater numbers can be catered to. Future research would benefit from the same inclusion and exclusion criteria. Finally, the lack of an online comparison treatment group presents another limitation of the current study.

Overall, the findings of the present study suggest that both modalities are equally efficacious in reducing overall levels of food cravings, the subjective power of food, levels of restraint, weight and BMI, as well as, lowering rates of anxiety, depression and somatic symptoms. There were some between groups' differences in the action of the treatment condition in effecting these changes, and the in-person group appeared to have achieved a slightly greater effect of weight loss, while the online group experienced greater effects for the treatment of somatic symptoms.

\section{Conflicts of Interest}

The authors declare no conflicts of interest regarding the publication of this paper.

\section{References}

Australian Medical Association (AMA) (2016). Obesity, 2016. https://ama.com.au/position-statement/obesity-2016

Barak, A., Hen, L., Boniel-Nissim, M., \& Shapira, N. A. (2008). A Comprehensive Review and a Meta-Analysis of the Effectiveness of Internet-Based Psychotherapeutic Interventions. Journal of Technology in Human Services, 26, 109-160. https://doi.org/10.1080/15228830802094429

Berger, T., Boettcher, J., \& Caspar, F. (2014). Internet-Based Guided Self-Help for Several Anxiety Disorders: A Randomized Controlled Trial Comparing a Tailored with a Standardized Disorder-Specific Approach. Psychotherapy, 51, 207-219. https://doi.org/10.1037/a0032527

Bodenlos, J. S., Lemon, S. C., Schneider, K. L., August, M. A., \& Pagoto, S. L. (2011). Associations of Mood and Anxiety Disorders with Obesity: Comparisons by Ethnicity. 
Journal of Psychosomatic Research, 71, 319-324.

https://doi.org/10.1016/j.jpsychores.2011.03.004

Bougea, A. M., Spandideas, N., Evangelos, C. A., Thomaideas, T., Chrousos, G. P., \& Darviri, C. (2013). Effect of the Emotional Freedom Technique on Perceived Stress, Quality of Life and Cortisol Salivary Levels in Tension-Type Headache Sufferers: A Randomized Controlled Trial. Explore, 9, 91-99. https://doi.org/10.1016/j.explore.2012.12.005

Cappelleri, J. C., Bushmakin, A. G., Gerber, R. A., Leidy, N. K., Sexton, C. C., Karlsson, J., \& Lowe, M. R. (2009). Evaluating the Power of Food Scale in Obese Subjects and a General Sample of Individuals: Development and Measurement Properties. International Journal of Obesity, 33, 913-922. https://doi.org/10.1038/ijo.2009.107

Chatwin, H., Stapleton, P., Porter, B., Devine, S., \& Sheldon, T. (2016). The Effectiveness of Cognitive Behavioral Therapy and Emotional Freedom Techniques in Reducing Depression and Anxiety among Adults: A Pilot Study. Integrative Medicine: A Clinician's Journal, 15, 27-34. http://www.imjournal.com

Christensen, H., Griffiths, K. M., \& Farrer, L. (2009). Adherence in Internet Interventions for Anxiety and Depression: A Systematic Review. Journal of Medical Internet Research, 11, e13. https://doi.org/10.2196/jmir.1194

Church, D. (2013). Clinical EFT as an Evidence-Based Practice for the Treatment of Psychological and Physiological Conditions. Psychology, 4, 645-654.

https://doi.org/10.4236/psych.2013.48092

Church, D., \& Brooks, A. J. (2010). The Effect of a Brief EFT (Emotional Freedom Techniques) Self-Intervention on Anxiety, Depression, Pain and Cravings in Healthcare Workers. Integrative Medicine: A Clinician's Journal, 9, 40-44.

http://www.imjournal.com

Church, D., \& Wilde, N. (2013). Emotional Eating and Weight Loss Following Skinny Genes, a Six-Week Online Program. Reported at the Annual Conference of the Association for Comprehensive Energy Psychology (ACEP), Reston, VA.

Church, D., Sparks, T., \& Clond, M. (2016). EFT (Emotional Freedom Techniques) and Resiliency in Veterans at Risk for PTSD: A Randomized Controlled Trial. Explore: The Journal of Science and Healing, 12, 355-365. https://doi.org/10.1016/j.explore.2016.06.012

Church, D., Stapleton, P., Sheppard, L., \& Carter, B. (2018). Naturally Thin You: Weight Loss and Psychological Symptoms after a Six Week Online Clinical EFT (Emotional Freedom Techniques) Course. EXPLORE, 14, 131-136. https://doi.org/10.1016/j.explore.2017.10.009

Clond, M. (2016). Emotional Freedom Techniques for Anxiety: A Systematic Review with Meta-Analysis. Journal of Nervous and Mental Disease, 204, 388-395. https://doi.org/10.1097/NMD.0000000000000483

Craig, G. (2010). The EFT Manual. Santa Rosa, CA: Energy Psychology Press.

Fabricatore, A. N., Wadden, T. A., Moore, R. H., Butryn, M. L., Heymsfield, S. B., \& Nguyen, A. M. (2009). Predictors of Attrition and Weight Loss Success: Results from a Randomized Controlled Trial. Behaviour Research and Therapy, 47, 685-691. https://doi.org/10.1016/j.brat.2009.05.004

Faul, F., Erdfelder, E., Lang, A. G., \& Buchner, A. (2007). G*Power 3: A Flexible Statistical Power Analysis Program for the Social, Behavioral, and Biomedical Sciences. Behavior Research Methods, 39, 175-191. https://doi.org/10.3758/BF03193146

Feinstein, D. (2012). Acupoint Stimulation in Treating Psychological Disorders: Evidence of Efficacy. Review of General Psychology, 16, 364-380. 
https://doi.org/10.1037/a0028602

Gariepy, G., Nitka, D., \& Schmitz, N. (2010). The Association between Obesity and Anxiety Disorders in the Population: A Systematic Review and Meta-Analysis. International Journal of Obesity, 34, 407-419. https://doi.org/10.1038/ijo.2009.252

Hedman, E., Ljótsson, B., Kaldo, V., Hesser, H., El Alaoui, S., Kraepelien, M. et al. (2014). Effectiveness of Internet-Based Cognitive Behaviour Therapy for Depression in Routine Psychiatric Care. Journal of Affective Disorders, 155, 49-58. https://doi.org/10.1016/j.jad.2013.10.023

Herman, C. P., \& Polivy, J. (1980). Restrained Eating. In A. J. Standard (Ed.), Obesity (pp. 208-225). Philadelphia: W.B. Saunders.

Honas, J. J., Early, J. L., Frederickson, D. D., \& O’Brien, M. S. (2003). Predictors of Attrition in a Large Clinic-Based Weight-Loss Program. Obesity, 11, 888-894. https://doi.org/10.1038/oby.2003.122

Kent, S., Fusco, F., Gray, A., Jebb, S. A., Cairns, B. J., \& Mihaylova, B. (2017). Body Mass Index and Healthcare Costs: A Systematic Literature Review of Individual Participant Data Studies. Obesity Reviews, 18, 869-879. https://doi.org/10.1111/obr.12560

Kroenke, K., Spitzer, R. L., \& Williams, J. B. (2001). The PHQ-9: Validity of a Brief Depression Severity Measure. Journal of General Internal Medicine, 16, 606-613. https://doi.org/10.1046/j.1525-1497.2001.016009606.x

Kroenke, K., Spitzer, R. L., \& Williams, J. B. (2002). The PHQ-15: Validity of a New Measure for Evaluating the Severity of Somatic Symptoms. Psychosomatic Medicine, 64, 258-266. https://doi.org/10.1097/00006842-200203000-00008

Laessle, R. G., Tuschl, R. J., Kotthaus, B. C., \& Prike, K. M. (1989). A Comparison of the Validity of Three Scales for the Assessment of Dietary Restraint. Journal of Abnormal Psychology, 98, 504-507. https://doi.org/10.1037/0021-843X.98.4.504

Linardon, J., Wade, T. D., de la Piedad Garcia, X., \& Brennan, L. (2017). The Efficacy of Cognitive-Behavioral Therapy for Eating Disorders: A Systematic Review and Meta-Analysis. Journal of Consulting and Clinical Psychology, 85, 1080-1094. https://doi.org/10.1037/ccp0000245

Locke, A. E., Kahali, B., Berndt, S. I., Justice, A. E., Pers, T. H., Day, F. R. et al. (2015). Genetic Studies of Body Mass Index Yield New Insights for Obesity Biology. Nature, 518, 197-206. https://doi.org/10.1038/nature14177

Lowe, M. R., Butryn, M. L., Didie, E. R., Annunziato, R. A., Thomas, J. G., Crerand, C. E. et al. (2009). The Power of Food Scale: A New Measure of the Psychological Influence of the Food Environment. Appetite, 53, 114-118.

https://doi.org/10.1016/j.appet.2009.05.016

Luppino, F. S., de Wit, L. M., Bouvy, P. F., Stijnen, T., Cuijpers, P., Penninx, B. W., \& Zitman, F. G. (2010). Overweight, Obesity, and Depression: A Systematic Review and Meta-Analysis of Longitudinal Studies. Archives of General Psychiatry, 67, 220-229. https://doi.org/10.1001/archgenpsychiatry.2010.2

McAuley, K. A., Smith, K. J., Taylor, R. W., McLay, R. T., Williams, S. M., \& Mann, J. I. (2006). Long-Term Effects of Popular Dietary Approaches on Weight Loss and Features of Insulin Resistance. International Journal of Obesity, 30, 342-349. https://doi.org/10.1038/sj.ijo.0803075

McLean, R. C., Morrison, D. S., Shearer, R., Boyle, S., \& Logue, J. (2016). Attrition and Weight Loss Outcomes for Patients with Complex Obesity, Anxiety and Depression Attending a Weight Management Programme with Targeted Psychological Treatment. Clinical Obesity, 6, 133-142. https://doi.org/10.1111/cob.12136 
Nelms, J. A., \& Castel, L. (2016). A Systematic Review and Meta-Analysis of Randomized and Nonrandomized Trials of Clinical Emotional Freedom Techniques (EFT) for the Treatment of Depression. EXPLORE: The Journal of Science and Healing, 12, 416-426. https://doi.org/10.1016/j.explore.2016.08.001

Patterson, S. (2016). The Effect of Emotional Freedom Technique on Stress and Anxiety in Nursing Students: A Pilot Study. Nurse Education Today, 40, 104-110.

https://doi.org/10.1016/j.nedt.2016.02.003

Provencher, V., Polivy, J., \& Herman, C. (2009). Perceived Healthiness of Food. If It's Healthy, You Can Eat More! Appetite, 52, 340-344.

https://doi.org/10.1016/j.appet.2008.11.005

Sebastian, B., \& Nelms, J. (2017). The Effectiveness of Emotional Freedom Techniques in the Treatment of Posttraumatic Stress Disorder: A Meta-Analysis. Explore, 13, 16-25.

https://doi.org/10.1016/j.explore.2016.10.001

Shaw, K., O’Rourke, P., Del Mar, C., \& Kenardy, J. (2005). Psychological Interventions for Overweight or Obesity. Cochrane Database System Review, 2, 1-75.

http://www.cochranelibrary.com https://doi.org/10.1002/14651858.CD003818.pub2

Sojcher, R., Fogerite, S. G., \& Perlman, A. (2012). Evidence and Potential Mechanisms for Mindfulness Practices and Energy Psychology for Obesity and Binge-Eating Disorder. Explore, 8, 271-276. https://doi.org/10.1016/j.explore.2012.06.003

Spiegelman, B. M., \& Flier, J. S. (2001). Obesity and the Regulation of Energy Balance. Cell, 104, 531-543. https://doi.org/10.1016/S0092-8674(01)00240-9

Spitzer, R. L., Kroenke, K., Williams, J. B. (1999). Patient Health Questionnaire Primary Care Study Group. Validation and Utility of a Self-Report Version of PRIME-MD: The PHQ Primary Care Study. JAMA, 282, 1737-1744.

https://doi.org/10.1001/jama.282.18.1737

Stapleton, P. B., Sheldon, T., \& Porter, B. (2012). Clinical Benefits of Emotional Freedom Techniques on Food Cravings at 12 Months Follow-Up: A Randomised Controlled Trial. Energy Psychology: Theory, Research, and Treatment, 4, 112.

https://energypsychologyjournal.org https://doi.org/10.9769/EPJ.2012.4.1.PS

Stapleton, P. B., Sheldon, T., Porter, B., \& Whitty, J. (2011). A Randomised Clinical Trial of a Meridian-Based Intervention for Food Cravings with Six-Month Follow-Up. Behaviour Change, 28, 1-16. https://doi.org/10.1375/bech.28.1.1

Stapleton, P., Bannatyne, A., Porter, B., Urzi, K. C., \& Sheldon, T. (2016). Food for Thought: A Randomised Controlled Trial of Emotional Freedom Techniques and Cognitive Behavioural Therapy in the Treatment of Food Cravings. Applied Psychology: Health and Well Being, 8, 232-57. https://doi.org/10.1111/aphw.12070

Stapleton, P., Bannatyne, A., Porter, B., Urzi, K. C., \& Sheldon, T. (2017). Secondary Psychological Outcomes in a Controlled Trial of Emotional Freedom Techniques and Cognitive Behaviour Therapy in the Treatment of Food Cravings. Complementary Therapies in Clinical Practice, 28, 136-145. https://doi.org/10.1016/j.ctcp.2017.06.004

Stapleton, P., Lilley-Hale, E.S., Mackintosh, G., \& Sparenburg, E (2019). Online Delivery of Emotional Freedom Techniques for Food Cravings and Weight Management: Two Year-Follow-Up. The Journal of Alternative and Complementary Medicine, 26.

Stapleton, P., Roos, T., Mackintosh, G., Sparenburg, E., \& Carter, B. (2019). Online Delivery of Emotional Freedom Techniques for Food Cravings and Weight Management, OBM Integrative and Complementary Medicine, 4, 31 . 
Strategic Advantages (2000). Symptom Assessment-45 Questionnaire (SA-45). New York, NY: Multi-Health Systems Inc.

Tabachnick, B. G., \& Fidell, L. S. (2013). Using Multivariate Statistics (6th ed.). USA: Pearson Education.

Teixeira, P. J., Going, S. B., Houtkooper, L. B., Cussler, E. C., Metcalfe, L. L., Blew, R. M. et al. (2004). Pretreatment Predictors of Attrition and Successful Weight Management in Women. International Journal of Obesity, 28, 1124-1133. https://doi.org/10.1038/sj.ijo.0802727

Tiggemann, M., \& Kemps, E. (2005). The Phenomenology of Food Cravings: The Role of Mental Imagery. Appetite, 45, 305-313. https://doi.org/10.1016/j.appet.2005.06.004

Wells, S., Polglase, K., Andrews, H. B., Carrington, P., \& Baker, A. H. (2003). Evaluation of a Meridian-Based Intervention, Emotional Freedom Techniques (EFT), for Reducing Specific Phobias of Small Animals. Journal of Clinical Psychology, 59, 943-966. https://doi.org/10.1002/jclp.10189

White, M. A., \& Grilo, C. M. (2005). Psychometric Properties of the Food Craving Inventory among Obese Patients with Binge Eating Disorder. Eating Behaviours, 6, 239-245. https://doi.org/10.1016/j.eatbeh.2005.01.001

White, M. A., Whisenhunt, B. L., Williamson, D. A., Greenway, F. L., \& Netemeyer, R. G. (2002). Development and Validation of the Food Craving Inventory. Obesity Research, 10, 107-114. https://doi.org/10.1038/oby.2002.17

Wolpe, J. (1973). The Practice of Behavior Therapy (2nd ed.). Elmsford, NY: Pergamon Press.

World Health Organization (WHO) (2017). Obesity and Overweight. Media Centre: Fact Sheet. http://www.who.int/mediacentre/factsheets/fs311/en/

Zellner, D. A., Loaiza, S., Gonzalez, Z., Pita, J., Morales, J., Pecora, D., \& Wolf, A. (2006). Food Selection Changes under Stress. Physiology \& Behavior, 87, 789-793.

https://doi.org/10.1016/j.physbeh.2006.01.014 